\author{
Anna Czapla \\ Katolicki Uniwersytet Lubelski Jana Pawła II
}

\title{
Geografia nazw patronimicznych na -ice a granice etniczne
}

\section{Stan badań}

Toponimy na *-itjo nie są specyficzną cechą nazewnictwa polskiego, w swych fonetycznych odmianach występują na całej Słowiańszczyźnie, przy czym obszarami ich znaczniejszego ilościowego nasilenia są, poza Polską, przede wszystkim Czechy, Morawy, regiony starego osadnictwa dawnej Jugosławii, zgermanizowane tereny zachodniolechickie i łużyckie, w znacznie mniejszym stopniu Ukraina i częściowo Białoruś. Niewielką ich liczbę odnotowano w Rosji, zwłaszcza północnej, Słowacji, na obszarach nowszego osadnictwa w Jugosławii oraz Bułgarii [Siciński 1972: 137].

Wiadomości na ten temat czerpać możemy z bogatej literatury. W okresie międzywojennym Stanisław Rospond opracował monografię tego typu dla Słowiańszczyzny Południowej oraz, już po wojnie, dla Śląska. Również po wojnie ukazało się omówienie nazw patronimicznych dla Mazowsza autorstwa Witolda Taszyckiego [Taszycki 1951]. W latach siedemdziesiątych Bogdan Siciński opracował stratygrafię polskich nazw patronimicznych, korzystając z już istniejących monografii [Siciński 1972: 136-138]. Zebrał kompletny zestaw nazw z pierwotnym sufiksem *-itjo (w tym też nazw niepatronimicznych typu Biskupice i etnicznych typu Zalesice), poświadczonych w dokumentach do XVI w. włącznie, z obszaru całej Polski (z pominięciem wąskiego pasa wzdłuż wschodniej granicy państwa, o historycznie niepolskim podłożu etnicznym, obejmującego wschodnie powiaty województw białostockiego, lubelskiego i rzeszowskiego, gdzie zresztą ten typ jest rzadki).

Współcześnie mamy już do dyspozycji więcej opracowań. W latach 90-tych ukazały się kolejne: monografia Pomorza, autorstwa Ewy Rzetelskiej-Feleszko i Jerzego Dumy [Duma, Rzetelska-Feleszko 1991], opracowanie Ireny Halickiej dotyczące Białostocczyzny [Halicka 1976], Barbary Czopek opisujące ziemię chełmską i bełską w granicach państwa polskiego [Czopek 1988] oraz monografie - wychodzące poza granice dzisiejszej Polski - ziemi dawnej Rzeczypospolitej 
w obrębie historycznego województwa ruskiego - sanockiej, opracowanej w latach osiemdziesiątych przez Władysława Makarskiego [Makarski 1986], przemyskiej tegoż samego autora z lat 90-tych [Makarski 1999], lwowskiej wydanej przed kilku laty [Czapla 2011] oraz halickiej będącej w opracowaniu.

\section{Nazwy patronimiczne na terenach etnicznie polskich}

Toponimy patronimiczne i matronimiczne oznaczają pierwotnie potomków lub poddanych człowieka, którego imię, przezwisko czy miana zawodu (godności) tkwi w nazwie miejscowej [Taszycki 1951: 263]. Są pluralnymi formami prostymi tworzonymi fleksyjnie od patronimików lub derywowanymi morfologicznie od niepatronimicznych mian osobowych. Między połową XIII a połową XIV w. dokonało się przejście tych toponimów z kategorii rzeczowników osobowych do kategorii rzeczowników rzeczowych. W miejsce form na -ici pojawiły się formy biernika na -ice. Proces ten spowodował zatarcie pierwotnego znaczenia patronimicznego [Rospond 1964: 18].

Obszar o największej produktywności toponimów patronimicznych na -ice w Polsce obejmuje Małopolskę [Rymut 1971], Śląsk [Rospond 1964] i Wielkopolskę [Siciński 1970: 136-138]; w pozostałych dzielnicach - na Mazowszu [Taszycki 1951], na Pomorzu - są one rzadkie [Duma, Rzetelska-Feleszko 1991].

Interesujący jest geograficzny układ nazw patronimicznych na Pomorzu. Najwcześniej poświadczone grupują się wokół okolicy miejscowości Wolin, mniej wyraźna jest koncentracja wokół Trzebiatowa i na linii Trzebiatów-Lobez. Dużo mniej jest tych nazw koło Stargardu Szczecińskiego i w ziemi pyrzyckiej [ibidem: 107].

Mazowsze nie jest terenem jednolitym pod względem częstotliwości występowania patronimicznych nazw miejscowych na -ice, ponieważ rozpada się ono na dwie części, południowo-zachodnią dobrze te nazwy znającą (województwo rawskie: powiat sochaczewski - 13,9\%, rawski - 14\%, gostyński $-6,5 \%$, województwo mazowieckie: powiat czerski $-5 \%$, grójecki $-6,6 \%$, warecki $-10,1 \%$, warszawski $-6,9 \%$, nowomiejski $-7,2 \%$, zakroczymski $-5,0 \%$, wyszogrodzki $-7,6 \%$, województwo płockie: powiat płoński $-5,2 \%$, płocki $-5,3 \%$, bielski 4,1\%, sierpecki - 5,1\%) [Taszycki 1951: 82-83] i północno-wschodnią, w której tylko sporadycznie występują. Granica między tymi dwoma częściami Mazowsza biegnie w przybliżeniu Wisłą po ujście Bugu, następnie Bugiem po ujście Narwi, dalej Narwią po ujście Orzyca i Orzycem po miejscowość Maków, wreszcie linią łączącą Maków z Sierpcem [ibidem: 84].

Zestawienie liczbowe według warstw chronologicznych patronimików mazowieckich i śląskich ilustruje zupełnie wyraźnie nieproduktywność pierwszych i wyraźną produktywność drugich. W XII w. na Mazowszu nie odnotowuje się powyższych, na Śląsku - 15, w XIII w. na Mazowszu - 21, na Śląsku - 278, 
w XIV w. na Mazowszu - 235, na Śląsku - 631 [Rospond 1964: 196]. Nieproduktywność mazowieckiego -ice tłumaczy się podobnie jak nieproduktywność tych nazw na jakimkolwiek terenie silnie zalesionym, piaszczystym czy mokrym, nienadającym się do uprawy roli, dopiero później przystosowanym pod częściową gospodarkę rolną. W każdej dzielnicy, nawet małopolskiej czy śląskiej o największym zagęszczeniu tych nazw są takie tereny.

Strefa największego nasilenia typu obejmuje w Wielkopolsce prawie całą ziemię Łęczycką, Sieradzką, Kujawy, powiaty centralne (Poznań, Września, Gniezno) i południowo-wschodnie (Krotoszyn, Pleszew, Kalisz). Powstaje w ten sposób niemal zwarty krąg z wyspą rzadszego występowania typu patronimicznego w rejonie Konina, Koła i zwłaszcza Słupcy. Najrzadziej nazwy te spotykamy obecnie i w przeszłości w Chodzieskiem, Czarnkowskiem, Międzychodzkiem, na Krajnie i na zachodnich obszarach, już w obrębie dzisiejszego województwa zielonogórskiego (Skwierzyna, Międzyrzecz) [Siciński 1972: 136-138].

$\mathrm{Na}$ terenie Małopolski, przyjmując jako tło porównania stan nazewnictwa małopolskiego z końca XVI w., trzeba stwierdzić, że średnia częstotliwość występowania w nim nazw patronimicznych wynosi 19,1\%. Na terenie dawnego województwa krakowskiego wraz z dawnym księstwem siewierskim średnia gęstość występowania nazw patronimicznych wynosiła $24,2 \%$, w dawnym województwie sandomierskim $16,3 \%$, a w dawnym województwie lubelskim 10,1\%. Widać z tego, że gęstość występowania nazw patronimicznych maleje z zachodu na wschód. Układając powiaty według częstotliwości występowania nazw patronimicznych, otrzymamy następującą kolejność: proszowicki - 39,9\%, śląski - 30,2\%, księski - 28\%, sandomierski - 25,1\%, księstwo siewierskie - 25\%, wiślicki - 23,4\%, szczyrzycki $22,3 \%$, lelowski - 20,3\%, chęciński - 17,6\%, opoczyński - 17,2\%, urzędowski $16,3 \%$, sądecki - 13,9\%, lubelski - 13,1\%, radomski - 12,7\%, pilzneński - 10,5\%, stężycki - 6,5\%, biecki - 6\%, łukowski-1,1\% [Rymut 1971: 93-94].

\section{Nazwy patronimiczne na pograniczu polsko-ruskim}

Nazwy patronimiczne na terenie Białostocczyzny tworzone były najczęściej za pomocą przyrostka -owięta/-ewięta - 52 nazwy, co stanowi 57,1\% wszystkich tego typu onimów. Przyrostek -ice tworzy 16 toponimów przede wszystkim od antroponimów o charakterze przezwiskowym, a przyrostek -owice/-ewice występuje w 17 nazwach pochodzących głównie od ich form skróconych [Halicka 1976: 205-207]. Nazwy patronimiczne na -ice występują przeważnie w pobliżu grodów i umocnień warownych $\mathrm{w}$ dawnym powiecie łomżyńskim i drohickim. Patronimica na -ęta występują w zwartej grupie na terenie między Bugiem i Narwią na zachód od linii Drohiczyn-Bielsk-Strabla, po granice ziemi mazowieckiej [ibidem: 227]. 
W ziemi przemyskiej podstawową grupę patronimików stanowią toponimy na -owice, -ewice < rus. -ewi (-y)či - 93 onimy; -i(-y)ce, -ycze < rus. $-i(-y) c ̌ c i-$ 53 nazwy; -ice lub -i(-y)nice - 6 nazw [Makarski 1999: 336-338], które łącznie stanowią 152 nazwy na 1200 punktów osadniczych, tj. 12,5\%. Na omawianym terenie $\mathrm{w}$ dużym nasileniu obecne są w powiatach jarosławskim, przemyskim, mościckim, gródeckim, starosamborskim, samborskim oraz drohobyckim, natomiast brak ich w powiecie łańcuckim i rzeszowskim.

Ziemia sanocka to 512 punktów osadniczych, wśród nich 11 nazw patronimicznych, ale tylko jedna $\mathrm{z}$ formantem -ice (Jędruszkowice w pow. sanockim), a pozostałe z formantem -ce (z powiatu sanockiego: Bykowce, Dudyńce, Jurowce, Kostarowce, Markowce, Pisarkowce, Rytarowce i z powiatu leskiego: Habkowce, Jankowce, Myczkowce) [Makarski 1986].

Ziemię chełmską i bełską w granicach państwa polskiego opracowała Barbara Czopek. W nazwach patronimicznych badanego terenu występuje 5 sufiksów: -ice/-ycze, -ce, -owice, -owce, -nice. Wszystkich nazw patronimicznych jest $59(100 \%)$. Najczęściej występujące przyrostki to -owice (28) i -ice (15), a rozmieszczone są na całym badanym terenie, jakkolwiek więcej ich występuje we wschodnich gminach zwłaszcza Hrubieszów, Werbkowice, Grabowiec [Czopek 1988: 70-75].

W ziemi lwowskiej [Czapla 2011: 266-268] formy nazw patronimicznych to przede wszystkim dwa podstawowe wzorce morfologiczne: -ice oraz -ce, z których pierwszy reprezentowany jest przez 66 nazw, drugi zaś przez 33 toponimy na 1145. Nazwy patronimiczne z sufiksem $-i(-y) c(z) e-66$ (z 97 wszystkich na $-i(-y)$ $c(z) e)$ pojawiają się na terenach atrakcyjnych osadniczo, przede wszystkim w powiatach: pustomytskim -17 , gródeckim -8 , przemyślańskim -7 , żydaczowskim -7 , złoczowskim -6 , samborskim -4 , jaworowskim -4 , mikołajowskim -3 , stryjskim -3 , nesterowskim -2 , buskim -1 , brzeżańskim -1 , zborowskim -1 , rohatyńskim -1 , brodzkim -1 .

Na terenie historycznej ziemi halickiej, będącej w opracowaniu, na prawie 1500 punktów osadniczych występuje około 13 nazw z formantem ice/-ycze. Są to Burczyce, pow. bursztyn, Chorostowice, zaginiona, Hinowice w pow. zaleszczyckim, Hnilice Mate i Hnilice Wielkie w zbarskim, Ihrowice i Myszkowice w tarnopolskim, Krostowice w rohatyńskim, Krzywice w przemyślańskim, Pałahicze w tłumackim, Szyszkowice w borszczowickim. Jest to zupełnie nieznaczny odsetek, przy którym właściwie nie ma jak mówić o stratygrafii tych nazw.

\section{Nazwy patronimiczne a próby ustalania granic etnicznych}

Argumentacja onomastyczna już niejednokrotnie wykorzystywana była do obrony poglądów o pierwotnej polskości czy ruskości ziem przygranicznych. Wykorzystywano w ten sposób typ na *-itji. Posłużył Henrykowi Łowmiańskiemu do 
nakreślenia dawnych ośrodków Sklawenów. Ten przyjął, że patronimica na *-itji stanowią archaiczny typ nazewniczy, odzwierciedlający ustrój rodowy, a ich produktywność wolno odnosić do czasów sprzed VIII w. Biorąc pod uwagę wszystkie toponimy patronimiczne, ustalił lokalizacje zagęszczenia tych nazw. Są one według niego wyznacznikiem starych obszarów osadniczych, a zatem również siedzib plemiennych, w tym Sklawenów nadsańskich, Dulebów - Bużan, Chorwatów. Natomiast na obszarach, gdzie takich nazw nie ma, według autora przebiegały podziały międzyplemienne. Tak było w rewirze Wisłoka, gdzie nadwiślańskich Chorwatów oddziela od wschodnich nadsańskich Sklawenów puszcza karpacka. Szeroka zona leśna, pozbawiona także nazw patronimicznych, rozpościera się wzdłuż obu brzegów Tanwi i Raty, odgraniczając zachodnich Łędzan od wschodniosłowiańskich Dulebów [Łowmiański 1967, IV: 18-40, 67-68, 133-137].

Na mapę nazw patronimicznych omawianego typu nakłada się na niektórych tych terenach rozkład nazw na -owce, -ińce. Ten typ form uznawany za wschodnio- i południowosłowiański - rejestrowany we wschodniej Słowacji, na Bałkanach i na różnych obszarach Ukrainy - sięga na zachód po okręg przemyski i sanocki. Rozmieszczenie to staje się dla autora podstawą do wyznaczenia wędrówki Sklawenów z ich najstarszych nadsańskich siedzib na wschód i na Bałkany, sięgającego być może już VI w. [Łowmiański 1970, IV: 280-281].

Teoria H. Łowmiańskiego została poddana surowej krytyce językoznawczej przez Kazimierza Rymuta [Rymut 1970: 289-297]. Jego zastrzeżenia budziło przesuwanie wszystkich nazw patronimicznych do czasów plemiennych. Jednak wiele $\mathrm{z}$ tych nazw opiera się na podstawach chrześcijańskich, a te pojawiły się po $\mathrm{X}$ w. Najbezpieczniej więc nazewnictwo z przeszłości rozpatrywać na podstawie danych filologicznych. Przy zastosowaniu tej dyrektywy żadna z tych nazw nie może być bez wątpliwości kojarzona z okresem sprzed VIII w.

Wyraźną zaś wskazówką co do ruskich zasięgów osadniczych może być współczesny nazwom patronimicznym na *-itji typ patronimików o ruskiej genezie -ovci, -inci. Ich uchwytna stratygrafia dotyczy, tak jak nazw na *-itji, również dopiero epoki poplemiennej [Wilkoń 1967: 70-83].

$\mathrm{Z}$ entuzjazmem do poglądów H. Łowmiańskiego nawiązał uczony ukraiński Oleh Kupczyński, który z rozmieszczenia nazw na *-itji uczynił główny argument w ustalaniu najdawniejszej mapy plemiennej Słowiańszczyzny [Kupczyński 1981: 149]. Widoczne na przedstawionej przez autora mapie strefy zagęszczenia nazw na *-itji [Kupczyński 1981: mapa 10], które istotnie świadczą o terenach sprzyjających osadniczo i być może o repartycjach plemiennych, nie muszą automatycznie wyznaczać granicy wschodniosłowiańsko-zachodniosłowiańskiej na linii Wisłoka, dolnego biegu Sanu, Wieprza i Bugu.

Inaczej wykorzystał ten wspólny dla języków typ nazewniczy Jerzy Nalepa, obrońca pierwotnej polskości szeroko rozumianego okręgu przemyskiego. Dla niego jest on wyznacznikiem dalekiego zachodniego zasięgu Słowiańszczyzny Zachodniej aż po górny Bug i Dniestr [Nalepa 1991: 29]. 
$\mathrm{Na}$ temat nazw patronimicznych zabrał jeszcze głos Zenon Leszczyński, ustalając aktualny zachodni zasięg nazw miejscowych typu -iče (Aleksicze, Klimkowicze, Krywiatycze) poprzedzonym przez -t-, na linii Łomża-Rzeszów [Leszczyński 2000: 123-129].

\section{Wnioski}

Wobec powyższych ustaleń, operując materiałem z mapy stratygraficznej nazw patronimicznych na -ice, musimy się powstrzymać od daleko idących wniosków historyczno-osadniczych, a jedynie możemy pozwolić sobie na ostrożne pytania o przeszłość.

Przedstawione zestawienie nazw patronimicznych na -ice z terenu współczesnej Polski i dawnej Rzeczpospolitej pokazuje wyraźnie ścisły związek nagromadzenia tychże z jakością terenu. Ponadto widać, że ilość nazw reprezentujących formant -ice zmniejsza się wyraźnie z zachodu na wschód. Wyjątek stanowi ich rozmieszczenie w południowo-wschodniej Polsce, mianowicie w ziemi przemyskiej brak ich w powiatach zachodnich - łańcuckim i rzeszowskim, a w dużym nasileniu obecne są w powiatach jarosławskim, przemyskim, mościckim, gródeckim, starosamborskim, samborskim oraz drohobyckim. Niezauważalna jest ich liczba w przyległej do ziemi przemyskiej ziemi sanockiej. Trudno na tej podstawie mówić o granicach etnicznych, zauważalny jest natomiast brak bezpośredniej łączności z odpowiednim typem małopolskim [Makarski 1999: 364].

Następnie w nieco bardziej na wschód położonej ziemi lwowskiej ich zasadnicza część koncentruje się wokół Lwowa, Gródka, na szlaku od Przemyśla do Lwowa [por. Posaćka-Czernichiwśka 1966: 39]. Obserwując te nazwy na terenie wszystkich zachodnich województw Ukrainy, na północ od Lwowa zajmują one terytorium pow. sokalskiego i rozprzestrzeniają się w kierunku Wołynia [ibidem: 40], a w położonej na południe ziemi halickiej wśród nazw patronimicznych króluje typ na -ce. Czym więc wytłumaczyć tę atrakcyjność toponimów na -ice na interesującym nas fragmencie dawnej Rzeczpospolitej?

Wiemy na pewno, że z 66 nazw patronimicznych z obszaru ziemi lwowskiej ani jedna nie posiada zapisu sprzed $1340 \mathrm{r}$. Nazwy na -ice są produktywne w okresie ożywionej ekspansji osadnictwa polskiego od drugiej poł. XIV w. do końca XVI w., czyli po powrocie ziemi lwowskiej do Polski, kiedy pojawia się znakomita większość toponimów. Podobnie rzecz się ma z nazwami patronimicznymi w ziemi przemyskiej [Makarski 1999: 306] oraz w ziemi chełmskiej i bełskiej, [Czopek 1988: 72], które to wraz z ziemią lwowską były najsilniej poddawane polskiej ekspansji. 


\section{Bibliografia}

Bučko Dmytro, 1972, Ukrainskije toponimy na -ivci, -inci, Lvov.

Czapla Anna, 2011, Nazwy miejscowości historycznej ziemi lwowskiej, Lublin.

Czopek Barbara, 1988, Nazwy miejscowe dawnej ziemi chetmskiej i betskiej (w granicach państwa polskiego), Wrocław-Warszawa-Gdańsk.

Halicka Irena, 1976, Nazwy miejscowe środkowej i zachodniej Białostocczyzny. Dzierżawcze, patronimiczne i rodzinne, Warszawa.

Janeczek Andrzej, 1978, Polska ekspansja w ziemi lwowskiej w XIV-XVI, „Przegląd Historyczny” 69, 4, 597-622.

Kupčyns'kyj Oleh, 1981, Najdavniši slovjans 'ki toponimy Ukrajiny jak džereto istoryko-heohrafičnych doslidžen' (Heohrafični nazvy na -yči), Kyjiv.

Leszczyński Zenon, 2000, Aktualny zasięg nazw miejscowych typu Aleksicze, Klimkowicze, Krywiatycze, [w:] Ewa Wolnicz-Pawłowska, Wanda Szulowska (red.), Kontakty językowe polszczyzny na pograniczu wschodnim, Warszawa, 123-129.

Łowmiański Henryk, 1967-1970, Początki Polski, t. 3-4, Warszawa.

Makarski Władysław, 1999, Nazwy miejscowości dawnej ziemi przemyskiej, Lublin.

Makarski Władysław, 1986, Nazwy miejscowości dawnej ziemi sanockiej, Lublin.

Nalepa Jerzy, 1991, Prapolski bastion toponimiczny w bramie przemyskiej i Lędzanie, „Onomastica" 36, 5-45.

Posaćka-Czernichiwśka E. M., 1966, Sproby kartohrafuvannia toponimiji L’vivszczyny, Onomastyka, 37-43, seria: Pytannia movoznavstwa, Kyjiv.

Rospond Stanisław, 1964, Patronimiczne nazwy miejscowe na Ślasku, Wrocław.

Rymut Kazimierz, 1971, Patronimiczne nazwy miejscowe w Małopolsce, Wrocław.

Rymut Kazimierz, 1970, Toponomastyka w stużbie badań historyczno-osadniczych (Na marginesie 3 t. Początków Polski H. Łowmiańskiego), „Onomastica” 15, $289-297$.

Rzetelska-Feleszko Ewa, Duma Jerzy, 1991, Dawne słowiańskie nazwy miejscowe Pomorza Szczecińskiego, Warszawa.

Siciński Bogdan, 1972, Stratygrafia polskich nazw patronimicznych, [w:] Atlas Onomastyczny Stowiańszczyzny. Księga referatów z konferencji Wrocław 1-3 VI 1970, „Prace Onomastyczne” $19,135-142$.

Taszycki Witold, 1951, Patronimiczne nazwy miejscowe na Mazowszu z mapa, Kraków.

Wilkoń Aleksander, 1967, Nazwy miejscowe typu Tyszowce, Witoszyńce w języku polskim, „Onomastica" 12, 70-83.

\section{Anna Czapla}

\section{Geographic location of the patronymic toponyms ending in -ice and ethnic boundaries}

\section{(Summary)}

The patronymic toponyms ending in -ice are the most productive in the Polish regions of Małopolska (Little Poland), Śląsk (Silesia) and Wielkopolska (Great Poland). These formations are relatively infrequent in the other two regions: Mazowsze (Mazovia) and Pomorze (Pomerania). The toponyms in question are not an exclusively Polish onomastic phenomenon. They are to be 
easily found in the other Slavic territories: in Czech Republic, Moravia, the countries of former Yugoslavia and in the Germanized west Lechitic and Lusatian territories. They are rather infrequent in the Ukraine and in some parts of Belarus. Do all these facts allow to make a general conclusion concerning the tribal borderline between the East and West Slavic zones? The facts we analyse have been used to defend the radical opnion taken by J. Nalepa, who claims of the originally Polish nature of the broadly understood region of Przemyśl, or by O. A. Kupczyński, who claims that the EastWest Slavic tribal borderline ran along the rivers Wisłok, lower San, Wieprz and Bug. W. Makarski claims that the fact of the geographical distribution of toponyms in -ice cannot decidedly answer the question about the tribal borderline, since genetically, the nature of the -ice formations is identical in all the regions, and an attempt to situate this onomastic problem in the tribal era raises serious objections. The distributional analysis of the patronymic toponyms in -ice in contemporary Poland and those in the territories of former Polish states reveals a close relationship between the accumulation of these toponyms with land quality, which is an obvious fact. One can observe a gradual decrease in the number of the -ice formations when moving from the West to the East of Poland. Exceptional in this respect is their relative accumulation in the South-Eastern Poland. They are frequent in the districts of Przemyśl, Jarosław, Moscice, Gródek Jagielloński, Stary Sambor, Sambor and Drohobycz, but they are not well represented in the districts of Łańcut or Rzeszów. Very few -ice toponyms are to be found in the region of Sanok, neighbouring the region of Przemyśl. All these facts make it hardly tenable to put forward any claims concerning ethnic borderlines. All that can be observed is the lack of link between the toponyms under analysis and the corresponding ones from the Little Poland.

Slowa klucze: nazwy patronimiczne, pogranicze polsko-ruskie.

Key words: patronymic toponyms, Polish-Ruthenian borderlands. 